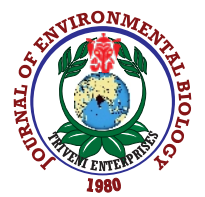

\title{
NDVI indicated changes in vegetation and their relations to climatic comfort factors in Demre-Akçay Sub basin, Turkey
}

\author{
A. Benliay', T. Yilmaz ${ }^{1 *}$, R. Olgun ${ }^{2}$ and M.K. Ak ${ }^{3}$ \\ 'Akdeniz University Faculty of Architecture, Department of Landscape Architecture, Antalya, 07070, Turkey \\ ${ }^{2}$ Akdeniz University, Serik G-S. Sural Vocational School of Higher Education, Department of Park and Horticulture, Antalya, 07500 , Turkey \\ ${ }^{3}$ Düzce University Faculty of Forestry Department of Landscape Architecture, Düzce, 81620, Turkey \\ *Corresponding Author Email : tahsin@akdeniz.edu.tr
} \begin{abstract}
an artificial neural network model. Vegetation Index (NDVI) values. Climatic comfort maps were created by ArcMap10.3 software using Kriging Method. Difference maps for climatic comfort and NDVI values of satellite images between 2006 - 2016 were created. At the pixel scale, these data were used for teaching artificial neural network model by Neural Designer software in randomly selected 500 points. All NDVI values $(-1-1)$ and possible vegetation changes $(-1-1)$ that could occurs in the study area were entered as input to the trained neural network model and the possible values of climate comfort change values were determined.

Results: Most significant $2006 \mathrm{NDVI}$ average and mean values were observed at 0.7, 0.6 and 0.5. In the value of NDVI in 2016 forecast, climatic comfort values could get higher in an area which can change into a mediocre or low vegetation value. The maximum average and mean values were 1.0, 0.9 and 0.8. This forecast shows that there could be positive and negative major changes between the climatic comfort values that may occur.

Interpretation: Artificial neural networks are the recent ways for such studies and are rapidly developing. Understanding artificial neural networks boundaries and advantages will allow for more efficient modeling tools. As in every part of life, the use of artificial neural networks is expected to increase day by day in landscape planning and design studies.
\end{abstract}

Abstract

Aim: The aim of this study was to evaluate the relationship between vegetation change obtained by NDVI analysis and climatic comfort factors by using

Methodology: Fethiye, Elmalı, Kaş, Finike, Kemer, Korkuteli, Antalya, Tefenni and Kale climatic station's temperature, humidity and wind data were evaluated during this study. Moreover, four Landsat TM satellite images (2006 - 2016) were used as 2 for each year to detect Normalized Difference

Key words: Artificial Neural Networks, NDVI, Climatic comfort

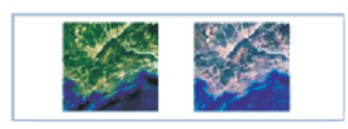

Satellite images for the years 2006-2016

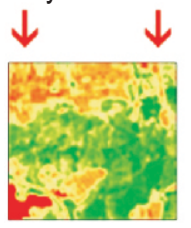

Differences in NDVI for the years 2006-2016

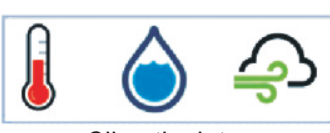

Climatic data for the years 2006-2016 $\downarrow \downarrow \downarrow$

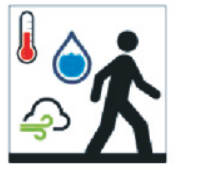

Differences in climatic confort for the years 2006-2016

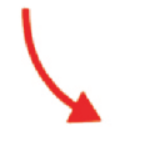

Artificial neural network model
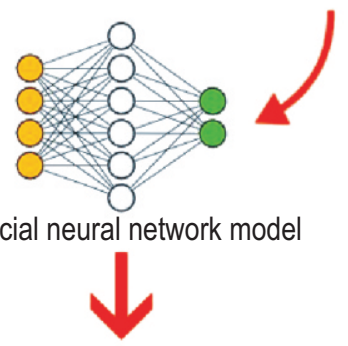

Prediction for all possible values of climate comfort change values

How to cite : Benliay, A., T. Yilmaz, R. Olgun and M.K. Ak: NDVI indicated changes in vegetation and their relations to climatic comfort factors in Demre-Akçay Sub basin, Turkey. J. Environ. Biol., 41, 344-350 (2020). 


\section{Introduction}

Urbanization in the world is increasing due to economic, political, technological and socio-political reasons (Ozturk et al., 1991, 2011; Ozturk and Caliskan, 2019). After industrial revolution, especially in the second half of 20th century, urbanization increased considerably. While $30 \%$ of the world's population lived in urban areas in 1950, in 2018 this ratio increased to $55 \%$. According to population projection realized for $2050,68 \%$ of the world's population is expected to live in urban areas (UN, 2018). Depending on these developments in the world, especially in Turkey after 1950, there has been tremendous increase in the urban population with migration from rural to urban areas. According to Turkish Statistical Institute (TUIK) data, $92.3 \%$ of the country's population lives in cities while $7.7 \%$ live in villages.

The cities are complex structures within certain system integrity that integrate natural, economic, social and ecological environments within a certain period and space (Nurlu et al., 2008; Zhang et al., 2011; Zou et al., 2012; Kanta and Zechman, 2014; Zhou et al., 2015; Olgun, 2018). In cities within this complex structure, increase in population density together with unplanned development due to industrialization cause the change of land cover/land use of cities in time and, thus, deterioration of natural and ecological structure. This deterioration in the city natural and ecological structure has been investigated by many researchers. They have examined relationship between the change of land cover/land use and local climate change in relation to temperature/other climatic parameters, population growth and population density relations in the cities (Liu and Deng, 2011; Zhang et al., 2013; Shi et al., 2015; Moradi and Gorer, 2017). Latest work in this connection shows that rapid urbanization and consequently vegetation loss have important effects on local and regional climate. In this context, the negative effects of urbanization and urban population growth accelerate climate change and cause global cycles to deteriorate (Grimm et al., 2008; Moradi and Gorer, 2017).

In addition, scientific studies have shown that increase in urban areas is effective on climate comfort provided by the city (Sarvestania et al., 2011; Emadodin et al., 2016; Bagheri and Nedae, 2018; Roshan et al., 2018). Evaluation of human comfort in the world shows that human life is mostly affected by the climate. Therefore, climate has significant effect on the behavior and physiological conditions of people. The climatic differences in urban areas affect the quality of life together with health, economy and recreation (Ghanghermeh et al., 2019). Climatic comfort expresses healthy and dynamic weather conditions for human mood and, hence, it is clearly related to the human satisfaction (Topay, 2013; Cetin, 2015; Cetin, 2016). In this context, people should be present in environments that have certain temperature, wind, and humidity range to be comfortable in their environment. This range is expressed as climate comfortzone (Boz, 2017).
The amount of thermal comfort temperature is calculated by activity, clothing levels of occupants, air velocity, air temperature and relative humidity. Missenard's Formula (Formula 1) can be used for outdoor thermal comfort temperature calculations for summer months. In this formula; the comfort temperature is between $16.8^{\circ}$ and $20.8^{\circ} \mathrm{TEE}$ for a person dressed lightly in the shade and resting. Under $16.8^{\circ}$ TEE records discomfort by cooling and over $20.8^{\circ} \mathrm{TEE}$, uncomfortable heat come to the forefront (Alam, 2014; Teodoreanu, 2016).

Formula 1. Formula Missenard

$\mathrm{TEE}=37-\frac{37-\text { ts }}{0.68+0.00014 \mathrm{f}+\left(\frac{1}{1.76+1.4_{v}^{0.75}}\right)}-0.29$ t.s $\left(1-\frac{f}{100}\right)$

TEE $=$ Thermal comfort value; $t s=$ Air tempature $\left({ }^{\circ} \mathrm{C}\right) ; \mathrm{f}=$ Relative humidity (\%); $v=$ Wind speed (m/sec.) (Teodoreanu, 2016).

The climatic condition of a region is directly proportional to the vegetation structure (Ali et al., 2017). Any change in the vegetation structure directly affects the increase or decrease of climatic comfort. Therefore, it is important to determine the change in vegetation structure of a region in order to determine the change in the climatic comfort over time. In addition to the use of different vegetation indices in studies on vegetation analysis, the use of Normalized Difference Vegetation Index (NDVI) analysis, which is free of topographic and atmospheric effects, is quite common (Duran, 2007; Pekkan, 2018). The NDVI analysis; as the ratio of infrared and near-infrared bands; provides an important source of data in terms of determining and evaluating the changes in the vegetation structure of land cover over a time scale. The value range of NDVI is -1 to 1 . Negative values of NDVI (values approaching -1) correspond to water. Values between 0.5 to -0.2 correspond to urban structures. Values close to zero (0.1 to 0.1 ) generally correspond to barren areas of rock, sand, or snow. Low positive values represent shrub and grassland $(0.2-0.4)$, while high values (values approaching 1$)$ indicate vegetation values such as temperate and tropical rainforests (Sentinel Hub, 2019).

The present study aimed to evaluate relationship between vegetation change obtained by NDVI analysis and climatic comfort factors by using an artificial neural network model.

\section{Materials and Methods}

The study area Demre - Akçay sub-basin is located in Antalya, Turkey, covering a total area of $6,144,242.8 \mathrm{~m}^{2}$. For this study the average values of July for years 2006 and 2016 temperature, humidity and wind speed data from Burdur, Fethiye, Elmalı, Kaş, Finike, Kemer, Korkuteli, Antalya and Kale meteorological stations were used to create climatic comfort maps. These stations are located in and around the study area. 
Also LC81780342016206, LC81780352016206 coded Landsat TM 8 (2016) and LT0517803520060729, LT0517803420060729 coded Landsat TM 5 (2006) satellite images were used to detect NDVI. Study area and location of meteorological stations are given in Fig. 1.

There are different methods used by researchers to examine the relationship between climatic comfort and vegetation changes. One of these methods is artificial neural network model. Artificial neural networks are application of artificial intelligence and have been used as an important tool in predicting the future; pattern recognition, data interpretation, optimization processes, non-linear function approaches for estimation of much variable-dependent time series (Sen, 2004; Sarıtekin and Sahin, 2016). Current studies in this field prove strong pattern classification and estimation capacity of artificial neural networks (Zhang, 2004; Aslay, 2013). In this context, the artificial neural network model is one of the powerful tools used to define the relationship between the change in vegetation and climatic comfort conditions on yearly basis.

Kriging Method was used to create average monthly temperature, humidity and wind data maps of July 2006 and 2016 in ArcMap 10.3 software. These maps were used for creating climatic comfort maps for each year with the use of Missenard Formula. The study area remains within the boundaries of two satellite images. The two orthorectified satellite images for the same date were merged into one mosaic raster data set for each year. Following this, the NDVI values for 2006 and 2016 were calculated for the study area. Difference maps for climatic comfort maps and NDVI values of satellite images between 2006- 2016 were created with the image difference tool in ArcMap 10,3 software.

At pixel scale, these data were used for teaching artificial neural network model by Neural Designer software in randomly selected 500 points from different maps. Quasi-Newton model is used as a training algorithm in an approximation project. All NDVI values of the year $2006(-1-+1)$ and possible vegetation changes $(-1-+1)$ that could happen in the study area were entered as input to the trained neural network model and the possible values of climate comfort change values were determined. As a result, the relationship between vegetation and climatic comfort change and the advantages and disadvantages of created artificial neural network model are discussed.

\section{Results and Discussion}

NDVI value calculations changed between -0.608011 and 0.633307 in the study area. Although distributions were heterogeneous, NDVI values decreased in coastal and residential areas but the values increased in inner parts of the study area which are mainly forests. As against this, the changes in thermal comfort maps were more homogeneous and increased all through the study area, however, in the inner parts values were higher (Fig. 2).

When the change in NDVI values was examined, the areas with less or no change in values, which are between -0.2 to 0.2 , occupied $71.30 \%$ of the study area. These areas were mainly

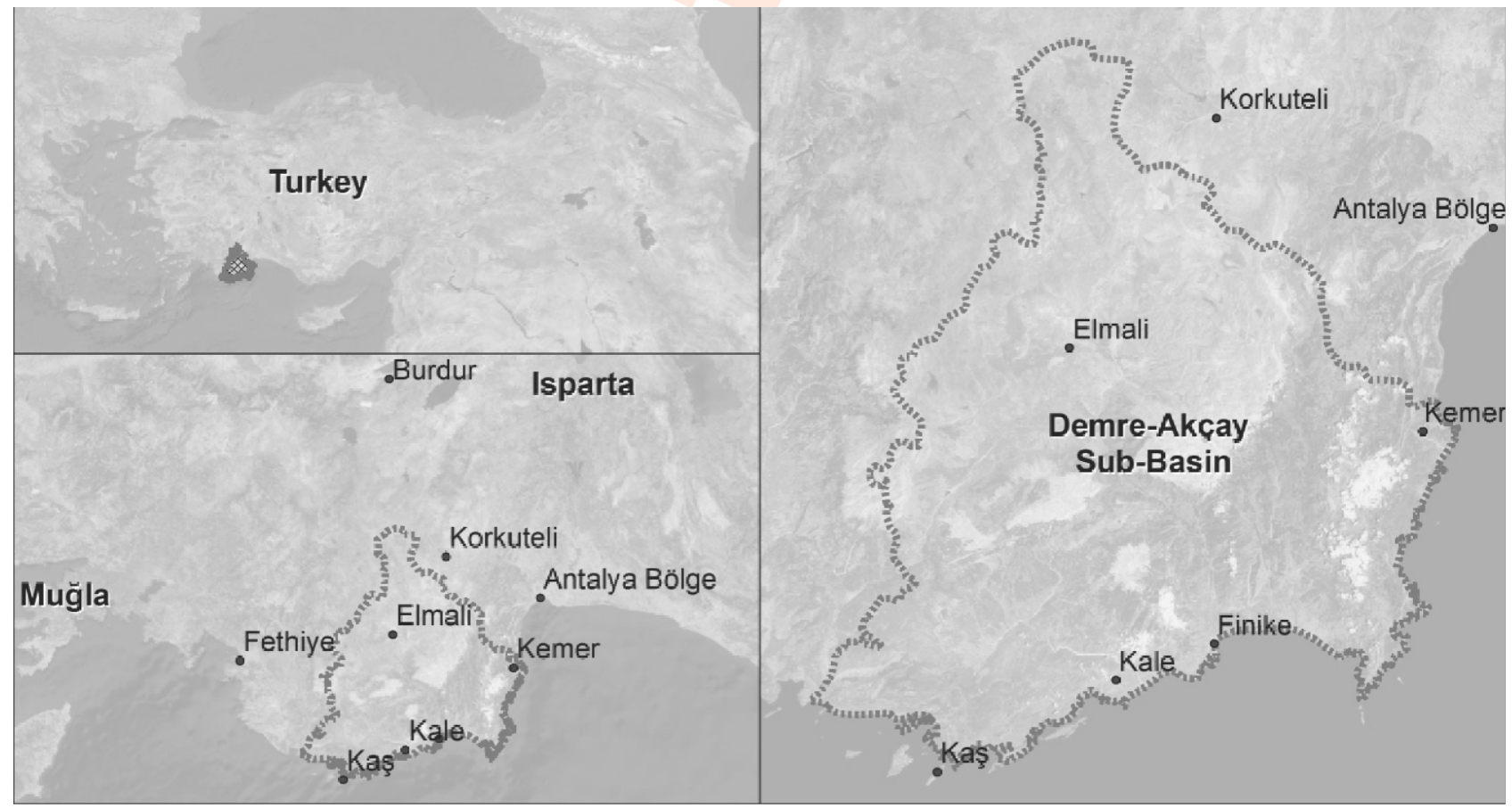

Fig. 1 : Demre-Akçay Sub-Basin and spatial distribution of meteorological stations. 


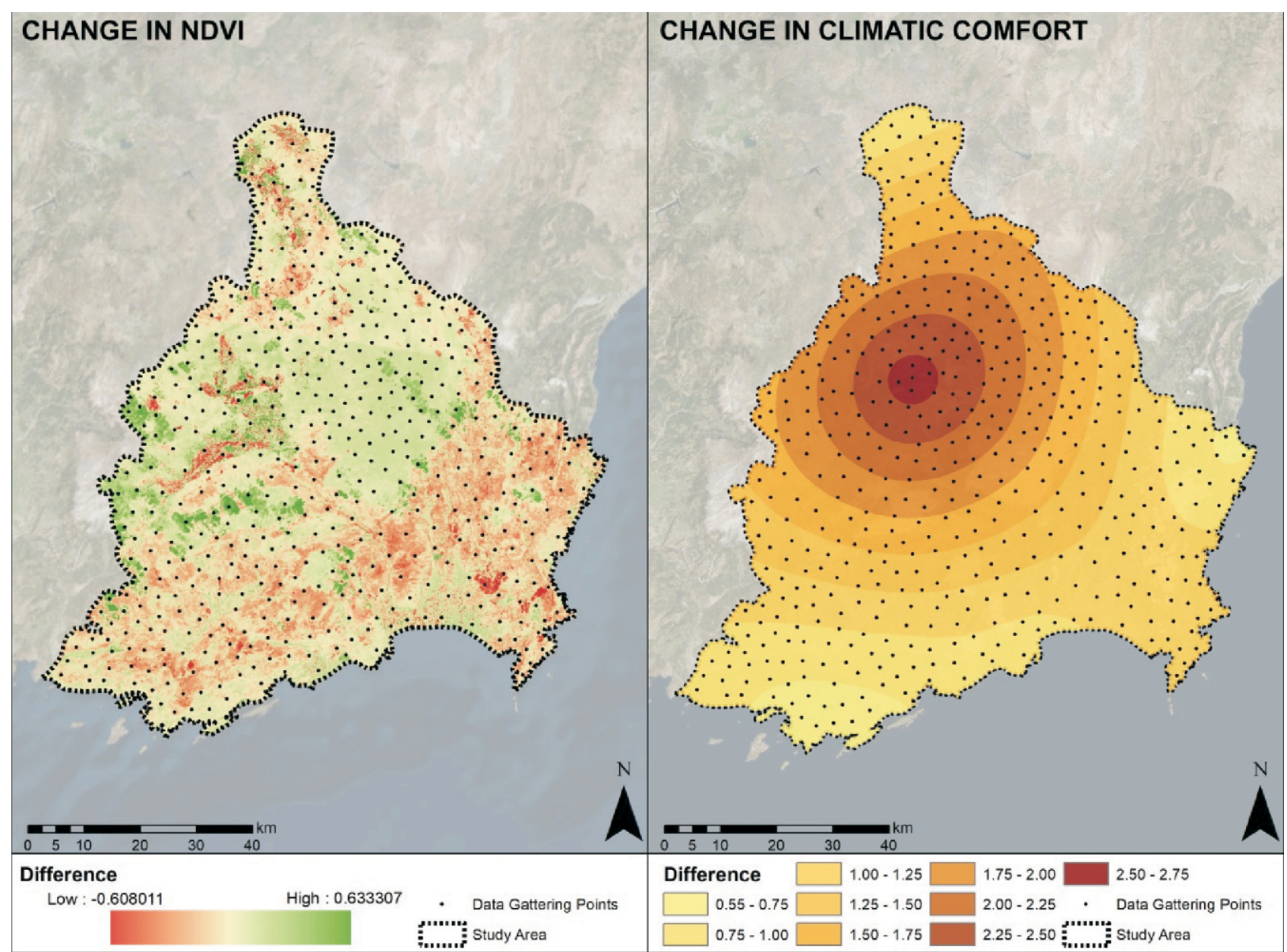

Fig. 2 : NDVI and climatic comfort value change maps.

Table 1 : Distribution of change in NDVI and climatic comfort values

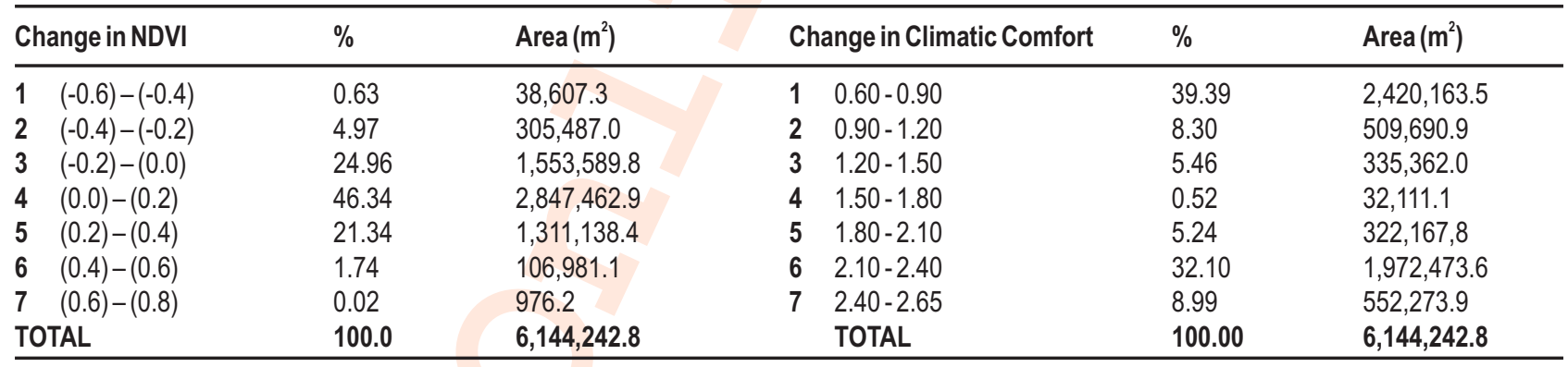

Table 2: Artificial neural network data set structure

\begin{tabular}{lllllllllll}
\hline & $\mathbf{1}$ & $\mathbf{2}$ & $\mathbf{3}$ & $\mathbf{4}$ & $\mathbf{5}$ & $\mathbf{6}$ & $\mathbf{7}$ & $\ldots$ & 499 & $\mathbf{5 0 0}$ \\
\hline NDVI (2006) & 0.061 & 0.197 & 0.030 & 0.112 & 0.031 & 0.034 & 0.093 & $\ldots$ & 0.224 & 0.132 \\
Difference in NDVI & 0.092 & 0.019 & 0.094 & 0.026 & 0.103 & 0.095 & 0.061 & $\ldots$ & 0.001 & 0.097 \\
Change in Comfort & 0.709 & 0.491 & 0.576 & 0.448 & 0.400 & 0.606 & 0.614 & $\ldots$ & -0.245 & -0.245 \\
\hline
\end{tabular}

vegetationless areas such as water bodies, sand dunes, rocky sites or urban areas. The regions where NDVI values increased mostly varied between 0.2 to 0.4 . This can be considered as expansion of vegetation in the land cover or growth of plant cover in the land, and this change had occurred in $21.34 \%$ of research area over a 10-year period is concentrated in the western and 
Table 3: Artificial neural network predictions for positive NDVI value of 2016

\begin{tabular}{|c|c|c|c|c|c|c|c|c|c|c|c|c|}
\hline \multicolumn{13}{|c|}{ NDVI VALUE OF 2016} \\
\hline & & 1.0 & 0.9 & 0.8 & 0.7 & 0.6 & 0.5 & 0.4 & 0.3 & 0.2 & 0.1 & 0.0 \\
\hline \multirow{21}{*}{ 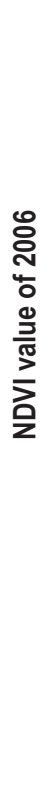 } & 1.0 & -2.17 & -2.19 & 0.32 & 0.28 & 0.28 & 0.28 & 0.29 & 0.67 & 0.74 & 1.39 & 1.44 \\
\hline & 0.9 & -2.17 & -2.17 & -2.52 & 0.28 & 0.28 & 0.28 & 0.29 & 0.61 & 0.79 & 1.38 & 1.42 \\
\hline & 0.8 & -2.18 & -2.17 & -2.17 & -1.49 & 0.28 & 0.28 & 0.29 & 0.56 & 0.82 & 1.34 & 1.29 \\
\hline & 0.7 & -15.30 & -2.37 & -2.17 & -2.18 & 0.36 & 0.28 & 0.28 & 0.51 & 0.83 & 1.24 & 0.71 \\
\hline & 0.6 & -15.55 & -15.52 & -6.69 & -2.16 & -2.28 & 0.29 & 0.28 & 0.48 & 0.82 & 0.82 & -1.73 \\
\hline & 0.5 & -5.46 & -9.56 & -15.13 & -14.22 & -1.98 & -3.05 & 0.29 & 0.45 & 0.74 & -0.87 & -0.12 \\
\hline & 0.4 & -6.29 & 0.86 & 2.71 & -5.85 & -9.47 & -0.19 & 0.30 & 0.43 & 0.21 & -2.07 & -1.84 \\
\hline & 0.3 & -2.59 & -2.76 & -1.55 & 4.98 & 4.78 & 0.41 & 0.64 & 0.37 & 0.50 & -2.74 & -2.67 \\
\hline & 0.2 & 0.72 & 0.82 & 1.06 & 1.61 & 3.81 & 5.14 & 4.96 & -0.48 & 0.56 & 0.32 & 0.01 \\
\hline & 0.1 & 0.29 & 0.29 & 0.30 & 0.31 & 0.36 & 0.55 & 0.55 & 1.26 & 0.74 & 0.72 & -2.11 \\
\hline & 0.0 & 0.29 & 0.29 & 0.29 & 0.32 & 0.49 & 0.85 & 0.66 & 0.41 & 0.55 & 0.45 & 1.63 \\
\hline & -0.1 & 0.29 & 0.29 & 0.31 & 0.44 & 0.84 & 0.63 & 0.39 & 0.57 & 0.58 & 0.54 & 1.09 \\
\hline & -0.2 & -0.05 & 0.27 & 0.40 & 0.78 & 0.58 & 0.42 & 0.53 & 0.68 & 0.61 & 0.54 & 0.54 \\
\hline & -0.3 & -0.56 & 0.05 & 0.33 & 0.59 & 0.49 & 0.49 & 0.67 & 0.70 & 0.63 & 0.54 & 0.55 \\
\hline & -0.4 & -2.68 & -0.16 & -0.01 & 0.22 & 0.45 & 0.65 & 0.70 & 0.71 & 0.64 & 0.53 & 0.55 \\
\hline & -0.5 & -4.99 & -2.55 & -1.45 & -0.05 & 0.22 & 0.70 & 0.71 & 0.71 & 0.66 & 0.53 & 0.55 \\
\hline & -0.6 & -3.56 & -3.54 & -0.65 & -0.15 & -0.13 & 0.66 & 0.71 & 0.71 & 0.67 & 0.53 & 0.55 \\
\hline & -0.7 & -2.65 & -2.02 & -0.25 & -0.78 & 0.21 & 0.54 & 0.71 & 0.71 & 0.68 & 0.53 & 0.54 \\
\hline & -0.8 & -1.25 & 0.55 & 0.22 & -0.22 & -0.11 & 0.05 & 0.70 & 0.71 & 0.69 & 0.53 & 0.54 \\
\hline & -0.9 & 1.25 & 1.01 & 0.98 & 1.55 & 0.98 & 0.65 & 0.70 & 0.70 & 0.68 & 0.52 & 0.54 \\
\hline & -1.0 & 1.98 & 1.34 & 2.89 & 2.35 & 1.77 & 1.12 & 0.68 & 0.70 & 0.67 & 0.51 & 0.54 \\
\hline \multirow{2}{*}{\multicolumn{2}{|c|}{$\begin{array}{l}\text { Average } \\
\text { mean }\end{array}$}} & -2.80 & -1.87 & -1.08 & -0.64 & 0.10 & 0.53 & 0.73 & 0.58 & 0.66 & 0.35 & 0.19 \\
\hline & & 4.57 & 3.87 & 3.70 & 3.63 & 2.60 & 1.30 & 0.96 & 0.30 & 0.14 & 1.01 & 1.19 \\
\hline
\end{tabular}

central regions. The biggest decrease in NDVI change was found in Kumluca and Adrasan region. The reason for this could be the forest fire that took place on 26 June 2016.

Climatic comfort values mainly differ between 0.60 to 0.90 and 2.10 to 2.40 in the study area. The values of these calculations changed between $0.55^{\circ}$ and $2.75^{\circ}$ TEE which is higher in Elmalı region. Distribution of change in NDVI and climatic comfort values are given in Table 1.

Data values for NDVI in the year 2006 for data gathering points were considered as the initial situation of the vegetation. In addition, change in NDVI and thermal comfort values between the years 2006 and 2016 were acquired from different maps. These data values have been altered for values between 0 and 1 for training the artificial neural network model (Table 2).

Similar to this study, Emmanuel (2003) found that strong and statistically significant trends exist in land use changes and climatic and bioclimatic changes. The model predicts that there could be a change in TEE values between $-15.55^{\circ}$ and $7.01^{\circ}$. While evaluating the forecast, there could be a decrease in TEE values, if the change in vegetation values are same or increase in the areas classified as high vegetation $(1.0-0.5)$ in $2006 \mathrm{NDVI}$. TEE values can decrease in the areas that are classified as rocky surfaces or urban areas in 2006, if the classifications are changed into high vegetation areas or water bodies. It is predicted that TEE values could increase to a smaller extent in most of the regions. It is foreseen that the increase in TEE values can be higher in the case of transformation of high vegetation areas to urban areas. These results are similar toGabor and Jombach's (2009)study. They stated that vegetation cover and land surface temperature are in strong negative correlation. It is also estimated that TEE values could increase in the areas which are classified as water bodies, even if they have transformed into areas with vegetation. This result is consistent with Wu and Zhang (2019)'s article. They have stated that thermal cooling effects decrease as the distance from the water bodies increases. Most significant $2006 \mathrm{NDVI}$ average and mean values are observed at 0.7, 0.6 and 0.5 , which can be interpreted as an area of mediocre features, as vegetation value is more important and also more sensitive to changes. Likewise, the climatic comfort values generally tend to increase in the change of high vegetation areas and water bodies.

In the value of NDVI in 2016 forecast, climatic comfort values could get higher in an area which can change into a mediocre or low vegetation value. Also the maximum average andmean values are as 1.0, 0.9and 0.8. This forecast shows that there could be positive and negative major changes between the climatic comfort values that may occur. The change in climatic comfort model which has been created with an artificial neural network model is given in Table 3 and Table 4. 
Table 4 : Artificial neural network predictions for negative NDVI value of 2016

\begin{tabular}{|c|c|c|c|c|c|c|c|c|c|c|c|c|}
\hline \multicolumn{13}{|c|}{ NDVI VALUE OF 2016} \\
\hline & & 0.0 & -0.1 & -0.2 & -0.3 & -0.4 & -0.5 & -0.6 & -0.7 & -0.8 & -0.9 & -1.0 \\
\hline \multirow{21}{*}{ 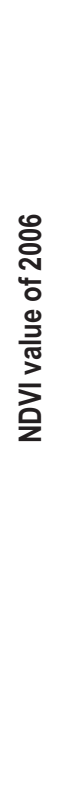 } & 1.0 & 1.44 & 1.95 & 2.45 & 3.11 & 4.67 & 7.01 & 4.10 & 1.02 & -0.10 & -1.50 & -1.47 \\
\hline & 0.9 & 1.42 & 1.23 & 1.25 & 2.55 & 3.66 & 6.02 & 3.26 & 0.77 & 0.15 & -1.22 & -1.22 \\
\hline & 0.8 & 1.29 & 0.44 & -0.94 & 0.25 & 2.88 & 4.22 & 3.77 & 0.87 & 1.22 & -1.21 & -1.33 \\
\hline & 0.7 & 0.71 & -2.74 & -1.88 & -0.71 & -1.22 & 1.99 & 1.88 & 0.44 & 0.88 & -0.95 & -0.98 \\
\hline & 0.6 & -1.73 & -1.00 & -0.40 & -1.17 & -2.82 & 1.25 & 1.05 & 0.22 & 0.55 & -0.55 & -1.68 \\
\hline & 0.5 & -0.12 & -1.26 & -2.35 & -0.86 & -0.78 & -0.77 & -0.88 & -1.08 & 0.47 & -0.22 & -1.55 \\
\hline & 0.4 & -1.84 & -2.15 & -1.33 & -1.14 & -1.06 & -1.01 & -0.96 & -2.88 & 0.22 & 0.01 & -1.73 \\
\hline & 0.3 & -2.67 & -0.52 & -1.35 & -2.13 & -2.81 & -3.34 & -3.72 & -4.95 & -0.65 & 0.05 & -1.68 \\
\hline & 0.2 & 0.01 & -0.11 & -0.20 & -0.30 & -0.42 & -0.57 & -0.75 & -0.97 & -1.24 & 0.11 & -1.66 \\
\hline & 0.1 & -2.11 & 1.96 & 1.41 & 1.89 & 0.84 & 0.44 & 0.28 & 0.21 & 0.17 & 0.14 & -2.01 \\
\hline & 0.0 & 1.63 & 3.12 & 1.48 & -0.80 & -2.01 & -1.90 & -1.84 & -1.29 & -1.07 & -3.51 & -2.44 \\
\hline & -0.1 & 1.09 & 0.43 & 1.49 & -3.06 & -3.47 & -3.35 & -2.03 & -1.74 & -1.68 & -1.69 & -1.71 \\
\hline & -0.2 & 0.54 & 1.34 & 1.20 & 1.22 & 0.16 & -3.95 & -7.03 & -4.27 & -2.28 & -1.78 & -1.68 \\
\hline & -0.3 & 0.55 & 2.12 & 1.38 & 1.36 & 1.55 & 1.42 & 0.03 & -6.78 & -6.97 & -5.40 & -2.68 \\
\hline & -0.4 & 0.55 & 0.54 & 1.42 & 1.38 & 1.38 & 1.38 & 1.98 & 1.61 & 0.50 & -7.98 & -5.71 \\
\hline & -0.5 & 0.55 & 0.55 & 0.53 & 1.38 & 1.38 & 1.38 & 1.38 & 2.41 & 1.97 & 1.77 & 0.99 \\
\hline & -0.6 & 0.55 & 0.55 & 0.55 & 2.14 & 1.38 & 1.38 & 1.38 & 1.38 & 1.42 & 2.45 & 1.98 \\
\hline & -0.7 & 0.54 & 0.55 & 0.55 & 0.55 & 1.51 & 1.38 & 1.38 & 1.38 & 1.38 & 1.38 & 1.13 \\
\hline & -0.8 & 0.54 & 0.55 & 0.55 & 0.55 & 0.54 & 1.39 & 1.38 & 1.38 & 1.38 & 1.38 & 1.38 \\
\hline & -0.9 & 0.54 & 0.55 & 0.55 & 0.55 & 0.55 & 0.06 & 1.38 & 1.38 & 1.38 & 1.38 & 1.38 \\
\hline & -1.0 & 0.54 & 0.55 & 0.55 & 0.55 & 0.55 & 0.55 & 1.76 & 1.38 & 1.38 & 1.38 & 1.38 \\
\hline \multirow{2}{*}{\multicolumn{2}{|c|}{$\begin{array}{l}\text { Average } \\
\text { mean }\end{array}$}} & 0.19 & 0.41 & 0.33 & 0.35 & 0.31 & 0.71 & 0.37 & -0.45 & -0.04 & -0.76 & -1.01 \\
\hline & & 1.19 & 1.36 & 1.25 & 1.52 & 2.06 & 2.70 & 2.52 & 2.39 & 1.91 & 2.41 & 1.77 \\
\hline
\end{tabular}

Artificial neural networks (ANN) have stepped in at global scale and are rapidly developing. As in every part of life, the use of artificial neural networks is expected to increase day by day in landscape planning and design studies. ANN compute any computable function by the appropriate selection of the network topology and weights values. This model can learn from experience that has been shaped by the interrelation of inputs and outputs. The initial NDVI values and change in NDVI data used as input, are numerical values between -1 and 1 . In other words, the model does not know which data are matched in a spatial manner in the study. Nevertheless, the data interpreted by the model contains significant results in terms of spatial characteristics. This study shows that ANN can adapt to unknown situations and model complex functions. Also, it is easy to use, learns by example, and needs very little user domain-specific expertise. The model created has its own practical results and each option has its own specific practical consequences. In this study, it has been estimated that the increase in the vegetation or water structures will cause a decrease in climatic comfort values. However, it is assumed that climatic comfort values will increase if vegetation decreases. Likewise, the values set forth suggest that there will be an increase in climatic comfort values even if land use does not change. This situation can be interpreted as a result of global warming. This study demonstrates the importance of vegetation in the land cover for climatic comfort values. In conclusion, understanding ANN boundaries and advantages will allow us for more efficient modeling tools. Identifying all possible changes in a region and calculating their TEE change values can be an important guide for decision makers. It should be considered that these results are formed by climate and vegetation land cover characteristics of the study area. Therefore, it is of great importance to carry out this type of studies for other regions and time intervals for a more efficient outcome.

\section{References}

Alam, S.: Impact of Clothing and Activity Level on Energy Consumption and Thermal Comfort on the Occupants in the Residential Building in Cold Climate Region. ASim 2014 International Building Simulation Association Asia Conference (IBPSA). November 28-29, Nagoya, Japan (2014).

Ali, S.B., S. Patnaik and O. Madguni: Microclimate land surface temperatures across urban land use/land cover forms. Global J. Environ. Sci. Manag., 3, 231-242 (2017).

Bagheri, B. and S. Nedae: An explanation of urban sprawl phenomenon in Shiraz metropolitan area (SMA). Cities, 73, 71-90 (2018).

Cetin, M.: Determining the bioclimatic comfort in Kastamonucity. Environ. Monit.Assess., 187, 640 (2015).

Cetin, M.: Determination of bioclimatic comfort areas in landscape planning: A case study of Cide Coastline. Tur. J. Agricul. - Food Sci. Technol., 4, 800-804 (2016).

Duran, C.: Plant cover analysis using remote sensing methods. Eastern Mediterr. Fore. Res. Instit., 13, 45-67 (2007).

Emadodin, I., A. Taravat and M. Rajaei: Effects of urban sprawl on local 
climate: A case study, North Central Iran. Urban Climate, 17, 230247 (2016).

Emmanuel, R.: Assessment of impact of land cover changes on urban bioclimate: the case of Colombo, Sri Lanka, Archit. Sci. Rev., 46, 151-158 (2003). doi: 10.1080/00038628.2003.9696978

Gábor P. and S. Jombach: The relation between the biological activity and the land surface temperature in Budapest. Appl. Ecol. Env. Res., 3, 241-251 (2009).

Ghanghermeh, A., G. Roshan, J.A. Orosa and A.M. Costa: Analysis and comparison of spatial-temporal entropy variability of Tehran city microclimate based on climate change scenarios. Entropy, 21, 1-21 (2019).

Grimm, N., S. Faeth, N. Golubiewski, C. Redman, J. Wu, X. Bai and J. Briggs: Global change and the ecology of cities. Science, 319, 756760 (2008).

Kanta, L. and E. Zechman: Complex adaptive systems framework to assess supply-side and demand-side management for urban water resources. J. WaterReso. Plann. Manage., 140, 75-85 (2014).

Liu, J. and X. Deng: Impacts and mitigation of climate change on Chinese cities. Curr. Opin. Environ. Sustainab., 3, 188-192 (2011).

Moradi, M. and T.N. Gorer: The urban growth effects over the local climate change in the case of Bursa. Planning, 27, 26-37 (2017).

Nurlu, E., U. Erdem, M. Ozturk, A. Guvensen and T. Turk: Landscape, demographic developments, biodiversity and sustainable land use strategy: A case study on Karaburun Peninsula, Izmir, Turkey. In: Use of Landscape Sciences for The Assessment of Environmental -Security (Eds.: I. Petrosillo et al.), Springer, The Netherlands, pp. 357-368 (2008).

Ozturk, M., U. Erdem and G. Gork: Urban Ecology. Ege Univ. Press, IZMIR, pp. 427 (1991).

Ozturk, M., A. Mermut and A. Celik: Land Degradation, Urbanisation, Land Use and Environment. NAMS \& T (Delhi-India), pp. 445 (2011).

Ozturk, S. and H. Caliskan: The impact of urbanization development on economic growth: The case of Turkey. Iğdır Univer. J. Soc. Sci., 17, 673-690 (2019).

Roshan, G., A. Ghanghermeh and Q. Kong: Spatial and temporal analysis of outdoor human thermal comfort during heat and cold waves in Iran. Weather Climate. Extrem., 19, 58-67 (2018).

Sarıtekin, N.K. and I. Sahin: Automatical implementation of artificial neural networks on hardware. Sakar. Univ. J. Sci., 20, 141-146 (2016)

Sarvestania, S., L. Ibrahima and P. Kanaroglou: Three decades of urban growth in the city of Shiraz, Iran: A remote sensing and geographic information systems application. Cities, 28, 320-329 (2011).

Sen, Z.: Principles of Artificial Neural Networks. Istanbul Water Foundation Publications, Istanbul (2004).

Sentinel Hub.: NDVI (Normalized Difference Vegetation Index). https://www.sentinel-hub.com/eoproducts/ndvi-normalizeddifference-vegetation-index (2019).

Shi, T., Y. Huang, H. Wang, C.E. Shi and Y.J. Yang: Influence of Urbanization on the thermal environment of meteorological station: Satellite-observed evidence. Advan. Clim. Chan. Res., 6, 7-15 (2015).

Teodoreanu, E.: Thermal comfort index. Pres. Environ. Sustain. Develop., 10, 105-118 (2016).

Topay M.: Mapping of thermal comfort for outdoor recreation planning using gis: The case of Ispartaprovince (Turkey). Turk. J. Agric. Fore., $37,110-120(2013)$

UN: World Urbanization Prospects: The 2018 Revision. https://population.un.org/wup/Publications/Files/WUP2018-Key Facts.pdf (2018).

Wu, Z. and Y. Zhang: Water Bodies' cooling effects on urban land daytime surface temperature: ecosystem service reducing heat island effect. Sustainability, 11, 1-11 (2019).

Zhang, G.P.: Neural Networks in Business Forecasting. Hershey, PA: Idea Group Publishing (2004).

Zhang, H., Z.F. Qi, X.Y. Ye, Y.B. Cai, W.C. Ma and M.N. Chen: Analysis of land use/land cover change, population shift, and their effects on spatiotemporal patterns of urban heat islands in metropolitan Shanghai, China. App. Geogr., 44, 121-133 (2013).

Zhang, Y., S. Li, B.D. Fath, Z. Yang and N. Yang: Analysis of an urban energy metabolic system: Comparison of simple and complex model results. Ecolo. Mode., 223, 14-19 (2011).

Zhou, D., J. Xu, L. Wang and Z. Lin: Assessing urbanization quality using structure and function analyses: A case study of the urban agglomeration around Hangzhou Bay (UAHB), China. Hab. Int., 49, 165-176 (2015).

Zou, Y., P.M. Torrens, R.G. Ghanem and I.G. Kevrekidis: Accelerating agent-based computation of complex urban systems. Inter. J. Geogr. Inform. Sci., 26, 1917-1937 (2012). 